\title{
Evaluation of Drug use Pattern and Behavior in Rural and Urban Population
}

\author{
P Rama*, Eldhose Jose, Jisni M Paul, Keerthana R, Geetha Raghava V \\ Department of Pharmacy Practice, PSG College of Pharmacy, Coimbatore, Tamil Nadu, INDIA.
}

\begin{abstract}
Background: Irrational use of medicines leads to problems such as ineffective treatment, health risks non-adherence, medication wastages, needless expenditure, improper storage and disposal of medicine. Self-medication and health care seeking behaviour pattern varies among different populations. Aim: The study aimed to evaluate the drug use pattern and behaviour in urban and rural population on behalf of their medication usage. Materials and Methods: A cross-sectional study was conducted with a validated questionnaire among 300 participants excluding healthcare professionals, 150 each from urban and rural areas of Coimbatore district, Tamil Nadu. Results: From the study we observed that $61.3 \%$ in urban and $58 \%$ in rural population had the habit of checking expiry date before using their medication. $80 \%$ and $57 \%$ of the participants carried their previous prescriptions during doctor visit in rural and urban community respectively. $3.3 \%$ of participants had the habit of suggesting and lending their medicines. $27.3 \%$ of rural and $14.6 \%$ of urban participants repurchased medicines with their previous prescriptions. $40.3 \%$ of participants were consulting pharmacists for drug information. Majority of our participants from both communities had a habit of disposing their unused or expired medications in trash. The prevalence of self-medication was $86.6 \%$ and $67.2 \%$ in urban and rural populations respectively. Conclusion: From the study we conclude that both the communities have imperfections with drug use practice such as Adherence, self-medication, drug disposal and repurchase of medications. This suggests the strong need for implementation of population need-based awareness programs in both the communities.
\end{abstract}

Key words: Self-medication, Adherence, Drug Disposal, Medicine Sharing, Drug use practice, Urban and Rural.

\section{INTRODUCTION}

Medicines are one of the vital tools needed to improve and maintain health and play a crucial role in saving life. However, for too many people throughout the world medicines are still unaffordable and unavailable. When available, $50 \%$ of patients fail to take their medicines appropriately. ${ }^{1}$ The practice of rational use of medicine is still in developing phase in many countries. People in these countries tend to have limited knowledge about medicine use and also tend lack awareness about safe handling and storing medicines at home. Due to the work burden, time pressure and financial crisis in developing communities, people tend to forget the medicines or fail to purchase the prescribed quantity of drugs or even stop taking medicines or take the wrong medicines. Inadequate communication between patients and health professionals due to time constraints leads to improper use of medicines.

The concept of "A PILL FOR EVERY ILL" still persists in many countries. Many people tend to take medicines immediately for all minor disease conditions. Vitamins and analgesics though relatively safe, are the most commonly used drugs in many countries. However, these kinds of practice also possess many risks.

Encouragement of self-care is seen as giving patients every opportunity to take responsibility and build confidence in their ability to manage their own health. Patient empowerment is viewed as a positive step in the development of the relationship between patient and healthcare provider and is considered as an important healthcare
DOI: 10.5530/ijopp.13.1.9

Address for correspondence: Prof. P Rama, Assistant Professor, Department of Pharmacy Practice, PSG College of Pharmacy Coimbatore641004, Tamil Nadu, INDIA. Phone no: +919600521266 Email Id: Keerthu.23.95@gmail. com

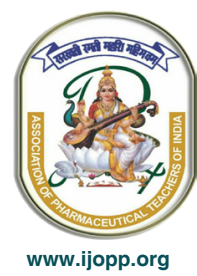


policy concept. ${ }^{2}$ The use of herbal medicines is a routine practice in many developing countries and in many parts of the world people combine herbal and modern pharmaceuticals claiming various benefits.

Self-medication is the consumption of medicinal products with the purpose of treating diseases or symptoms, or even promoting health, without a prescription provided by a medical professional. A number of reasons could be enumerated for the rise in practice of self-medication. One of the reasons being the increase in chronic diseases and their incidence has raised from $30 \%$ to $80 \%$ in the last 40 years. Some studies have pointed that people who have suffered from minor illness previously tend to practice self-medication more. Other reasons which are responsible for self-medication in developing countries are urge of self-care, feeling of sympathy towards family members in sickness, lack of health services, poverty, ignorance, misbelieves, use of drugs from informal sectors such as open markets and quacks. Medicines are stored in many households for various purpose including emergency use and treating other illness. However, not only the OTC drugs are occupants of household medicine kits, there are also medicines from leftover prescription. Unused/ leftover medications at home are the results of excessive buying of OTC drugs, self-discontinuation and expiration of drugs which is responsible for wastage of drug at home. ${ }^{3}$ These leftover medicines when stored in uncontrolled environment may degrade to less active or even toxic substance. The limited knowledge on proper drug storage and its use and presence of medicines at home is likely to fuel the irrational drug use mainly due to unintentional use among household members.

People talk to each other about therapies, creating and reinforcing existing drug use cultures and they rely on local sources of drugs. People are aware of medicines that are needed for common medical problems and they obtain them at local drug stores, general shops or the market.

With the diversity among human population, even the self-medication and health seeking behaviour pattern varies among different populations and are influenced by many factors like age, gender, education, family, society, law, availability of drugs, exposure to advertisements and nature of illness.

\section{MATERIALS AND METHODS}

\section{Methodology}

A cross-sectional study was conducted in Coimbatore district of Tamil Nadu, India during the year 2018 after Institutional Human Ethics Committee (IHEC) approval. Data were collected from 300 Participants (above 18 years of age), 150 each from urban and rural areas (Peelamedu and Vedapatti) respectively and then analyzed for the details of practice of self-medication, checking of expiry date, medicine storage, place of storage, source of selfmedication, medicine sharing and disposal pattern.

Exclusion Criteria: Healthcare professionals were excluded from the study.

Data Collection: 360 participants were approached out of which data was collected from 300 participants. A structured validated questionnaire was used as a tool for data collection.

Data Analysis: Data was analyzed by percentage calculation and Chi square test using SPSS (Statistical Package for Social Sciences) version 16.

\section{DISCUSSION}

A total of 300 responses were collected from both rural and urban communities. Out of the total responses, the majority of responses were from the age group of 18-28 years $(32.6 \%)$. Gender wise distribution of respondents showed $52.3 \%$ were males and $47.7 \%$ were females. Out of 150 respondents from each population $21.9 \%$ were non graduates and $78 \%$ were graduates in urban population, whereas $80 \%$ and $20 \%$ of the rural respondents were non graduates and graduates respectively.

In our study we focused on personal interview with the participants to analyse their medication use behaviours such as self-medication, drug adherence, storage and disposal practices.

In the study conducted by Varsha A Prabhu et al. in Karnataka, among the respondents, $42.50 \%$ of the population had the practice of checking the expiry dates of the medicines before using them. ${ }^{4}$ From our study it is found that $61.3 \%$ and $25.3 \%$ in urban and $58 \%$ and $15.3 \%$ of rural population has the habit of checking expiry date always and sometimes respectively before using their medications. A small difference in the both population may be attributed to their education (Table 1).

A drug utilization study conducted in western India by Nazima Mirza et al. stated that urban people followed appropriate dose and duration of medicines more significantly than the rural population. ${ }^{5}$ from our study it is observed that the urban population is more adhered to the duration of treatment compared to the rural population. This may be because of more exposure and communication of urban population to the health care system compared to the rural population.

Indian Journal of Pharmacy Practice, Vol 13, Issue 1, Jan-Mar, 2020 


\section{Table 1: Questionnaire response of study participants.}

\begin{tabular}{|c|c|c|c|c|}
\hline \multirow{2}{*}{ S.No } & \multirow{2}{*}{ Question } & \multirow{2}{*}{$\begin{array}{l}\text { Response } \\
\text { Percentage }\end{array}$} & \multirow{2}{*}{$\begin{array}{c}\text { Rural } \\
\text { Percentage }\end{array}$} & \multirow[t]{2}{*}{ Urban } \\
\hline & & & & \\
\hline \multirow[t]{3}{*}{1} & \multirow{3}{*}{$\begin{array}{c}\text { Do you check the expiry date before } \\
\text { you use the medicine? }\end{array}$} & Always & 58 & 61.3 \\
\hline & & Sometimes & 15.3 & 25.3 \\
\hline & & Never & 26.6 & 13.3 \\
\hline \multirow[t]{3}{*}{2} & \multirow{3}{*}{$\begin{array}{l}\text { Do you complete the course of } \\
\text { treatment as per doctor's advice? }\end{array}$} & Always & 55.3 & 54.6 \\
\hline & & Sometimes & 16 & 34.6 \\
\hline & & Never & 28.6 & 10.6 \\
\hline \multirow[t]{3}{*}{3} & \multirow{3}{*}{$\begin{array}{c}\text { Do you wash your hands before } \\
\text { taking medicines? }\end{array}$} & Always & 35.3 & 29.3 \\
\hline & & Sometimes & 22 & 33.3 \\
\hline & & Never & 42.6 & 37.3 \\
\hline \multirow[t]{3}{*}{4} & \multirow{3}{*}{$\begin{array}{l}\text { When you visit a doctor, will you bring } \\
\text { all medications / prescription you are } \\
\text { currently taking? }\end{array}$} & Always & 53.3 & 38 \\
\hline & & Sometimes & 18 & 31.3 \\
\hline & & Never & 28.6 & 30.6 \\
\hline \multirow[t]{3}{*}{5} & \multirow{3}{*}{$\begin{array}{c}\text { Do you alter the doses of medications } \\
\text { based on your symptoms without } \\
\text { asking your doctor? }\end{array}$} & Always & 18.6 & 6 \\
\hline & & Sometimes & 20 & 26.6 \\
\hline & & Never & 61.3 & 67.3 \\
\hline \multirow[t]{3}{*}{6} & \multirow{3}{*}{$\begin{array}{l}\text { Do you clarify about your medicines } \\
\text { with the pharmacist before you take } \\
\text { them? }\end{array}$} & Always & 45.3 & 35.3 \\
\hline & & Sometimes & 15.3 & 30 \\
\hline & & Never & 39.3 & 39.3 \\
\hline \multirow[t]{3}{*}{7} & \multirow{3}{*}{$\begin{array}{l}\text { Do you re purchase medicines with } \\
\text { old prescription? }\end{array}$} & Always & 27.3 & 14.6 \\
\hline & & Sometimes & 23.3 & 41.3 \\
\hline & & Never & 49.3 & 44 \\
\hline \multirow[t]{3}{*}{8} & \multirow{3}{*}{$\begin{array}{l}\text { Do you give your prescription } \\
\text { medicines to others? }\end{array}$} & Always & 2 & 3.3 \\
\hline & & Sometimes & 13.3 & 20 \\
\hline & & Never & 84.6 & 76.6 \\
\hline \multirow[t]{3}{*}{9} & \multirow{3}{*}{$\begin{array}{l}\text { Have you missed a before food } \\
\text { medicine and taken it after food? }\end{array}$} & Always & 15.3 & 13.3 \\
\hline & & Sometimes & 28 & 46.6 \\
\hline & & Never & 56 & 40 \\
\hline 10 & Do you keep stock of other & Always & 29.3 & 25.3 \\
\hline & medicines? & Sometimes & 22 & 41.3 \\
\hline & & Never & 48.6 & 33.3 \\
\hline 11 & When you feel sick, will you ask & Always & 32.6 & 32.6 \\
\hline & $\begin{array}{c}\text { for medicınes trom pharmacy by } \\
\text { yourself? }\end{array}$ & Sometimes & 34.6 & 54 \\
\hline & & Never & 32.6 & 19.3 \\
\hline 12 & Which one do you prefer? & Injection & 42.6 & 38.6 \\
\hline & & Tablet & 57.3 & 61.3 \\
\hline 13 & How do you deal with left-over & Keep Them & 18.6 & 24 \\
\hline & (unused / expired) medicines? & Return Them to Pharmacy & 11.3 & 4 \\
\hline & & Throw Them & 70 & 72 \\
\hline 14 & What do you do if you miss a dose? & Skip the Dose & 68.6 & 60 \\
\hline & & Taken When Remembered & 19.3 & 29.3 \\
\hline & & Taken with Next Dose & 12 & 10.6 \\
\hline 15 & How will you take a oral tablet or & With Water & 90.6 & 89.3 \\
\hline & capsule? & With Tea or Milk & 5.3 & 4 \\
\hline & & With Soft Drinks & 1.3 & 3.3 \\
\hline & & With Food & 2.5 & 3.3 \\
\hline
\end{tabular}




\section{Table 1: Con's}

\begin{tabular}{|c|c|c|c|c|}
\hline \multirow[t]{3}{*}{16} & \multirow{3}{*}{$\begin{array}{l}\text { Do you have a different place for } \\
\text { keeping medications? Where? }\end{array}$} & Box & 44 & 60.6 \\
\hline & & Open in Shelf & 26 & 20 \\
\hline & & Open in Table & 30 & 19.3 \\
\hline \multirow[t]{4}{*}{17} & \multirow{4}{*}{$\begin{array}{l}\text { Do you use any other type of } \\
\text { medicines other than allopathic } \\
\text { medicines? If yes, what? }\end{array}$} & Homeopathy & 15.3 & 16.6 \\
\hline & & Ayurvedha & 15.3 & 38 \\
\hline & & Siddha & 12.6 & 5.3 \\
\hline & & None of these & 56.6 & 40 \\
\hline \multirow[t]{2}{*}{18} & \multirow{2}{*}{$\begin{array}{l}\text { Does taking medicines before food } \\
\text { and after food have the same effect? }\end{array}$} & Yes & 42 & 35.3 \\
\hline & & No & 58 & 64.6 \\
\hline \multirow[t]{3}{*}{19} & \multirow{3}{*}{$\begin{array}{l}\text { What will you do in case you } \\
\text { experience a side effect? }\end{array}$} & Inform the Doctor & 77.3 & 67.3 \\
\hline & & Stop the Medicine & 17.3 & 30 \\
\hline & & Continue the Medicine & 5.3 & 2.6 \\
\hline \multirow[t]{4}{*}{20} & \multirow{4}{*}{$\begin{array}{l}\text { What is the motivation/information } \\
\text { source for self-medication? }\end{array}$} & Previous Prescription & 56 & 56 \\
\hline & & Advertisement & 14 & 6.6 \\
\hline & & Friends & 18 & 27.3 \\
\hline & & None of These & 12 & 10 \\
\hline
\end{tabular}

Past medication history records aids the physician to understand the patient's condition better and also to design the appropriate drug regimen. In our study it is observed that $(80 \%$ and $57 \%$ ) of the participants take their previous prescriptions during doctor visit in rural and urban community respectively (Table 1$)$. It is also taken into account that urban people prefer the hospitals which usually have a functional medical record department where rural population consults more in clinics were patient has to take care of his/her medical history documents. When people consult different physicians, it is preferred to update the physician about the past and current treatment the patient has received.

A drug utilization study conducted in a part of western India by Kaushal J shows that, 59\% of participants did not adhere to instructions given by the prescriber regarding dose, frequency and duration of treatment. ${ }^{3}$ In contrast to their observation our study showed that only $10.6 \%$ and $28.6 \%$ of participants were not adhered properly to the instructions given by the physician regarding the dose, frequency and duration of treatment in both urban and rural community respectively.

Study by Kebede A. Beyene documented high prevalence rates of medication lending (6\%-22.9\%) and borrowing practices $(5 \%-51.9 \%) .^{6}$ In our study it is found that only $2 \%-3.3 \%$ of participants had the habit of suggesting and lending their medicines to others.

In the study conducted by Omar T Dawood et al. in Malaysia, participants reported that they never reuse their old prescription and believed that old prescription medications are not as effective as new medications. ${ }^{7}$ In contrast, our study showed that $27.3 \%$ of participants in rural and $14.6 \%$ of participants in urban community repurchased medicines with their previous prescriptions and this was found to be a major source for selfmedication (Figure 3). The same study also showed that, most of the participants were not aware of the side effects of their medicines and stated that they had never experienced any side effects, while chronic disease participants who reported the side effects of medicines stopped using medications without informing their doctors. However, from our study it is seen that $72.3 \%$ of participants reported that they would inform their doctor whenever they experience any side effect and $23.6 \%$ of participants reported that they would stop using medicines if they experiences any side effect (Table 1).

From the study conducted by Fatemeh Soleymani et al. ${ }^{8}$ showed the people's false belief about drug, such that they believed injectable form of medicines are more effective than oral forms. In a similar way our study also shows that $40.6 \%$ of total participants preferred injections more than the oral forms. Participants also informed that they intentionally ask their doctors to prescribe injection form over tablet so that they get faster relief from their illness. This may cause extra treatment burden to the healthcare set up and increases the injection related safety hazards. Rest of the population preferred tablet because of it's ease of use and cost effectiveness.

Study conducted by Muhammad Umair Khan et al. showed that, $51.8 \%$ participants interacted with pharmacist on regular basis. This finding also showed that $84.1 \%$ of participants agreed that pharmacists are important part of health care system. ${ }^{9}$ Related to this study we 
have assessed whether participants are consulting with pharmacists before taking their medicines and we found that $40.3 \%$ of participants were consulting pharmacists for drug information services in community. Training and awareness programmes should be implemented to develop pharmacy practice sector in community.

In a study conducted by A Akici et al. $41.0 \%$ of participants declared to keep their unused drugs at home,${ }^{10}$ whereas in our study comparatively less amount $19.2 \%$ of participants kept their unused medicines in home. We found a significant association between medicine storage and self-medication practice.

A study in the United States (US) reported that $85.0 \%$ of participants threw their drugs in trash, sink, or toilet (Law et al. 2015). ${ }^{11}$ In similar way majority of our participants $(73.45 \%)$ had a habit of disposing their unused or expired medications in trash.

A study conducted by Mohammed Imran titled 'The prevalence and patterns of usage of Ayurveda, Unani and home remedies in younger adults of rural North India stated that $53 \%$ participants had used alternate medicine therapy in combination with Allopathy. ${ }^{12}$ Similar to this, our study showed that $43.3 \%$ of rural population and $59 \%$ of urban population used other system of medicines, in which, practice of Ayurvedha is more prevalent in urban population whereas rural population practice both Ayurvedha and Siddha in a similar fashion. This increase in use of other system of medicine can be attributed to the long-standing belief that these natural system of medicines have less side effects when compared to the allopathic system.

In a study conducted by Banerjee I et al. antibiotics were the most frequently used drugs for self-medication, whereas in our study acetaminophen, cold medicines and NSAIDs were found to be frequently used (Figure 1) $\cdot{ }^{13} \mathrm{In}$ a study conducted by Dnyanesh Limaye, the prevalence of self-medication was found to be $29.1 \%, 51.5 \%, 7.7 \%$ in total, urban and rural study population respectively. ${ }^{14}$ Similarly our study showed that the prevalence of selfmedication was $74.2 \%, 81.2 \%$ and $67.2 \%$ in total, urban and rural study population respectively, with higher proportion being used in urban community where the possible reasons being easy access to health care set up, high literacy rate (Figure 2).

A study conducted by Aqeel et al. shows that there was statistically insignificant difference among different age groups in the use of self-medication, ${ }^{15}$ however, generally a higher portion of young participants indulged in selfmedication. Similarly, our study too showed that higher

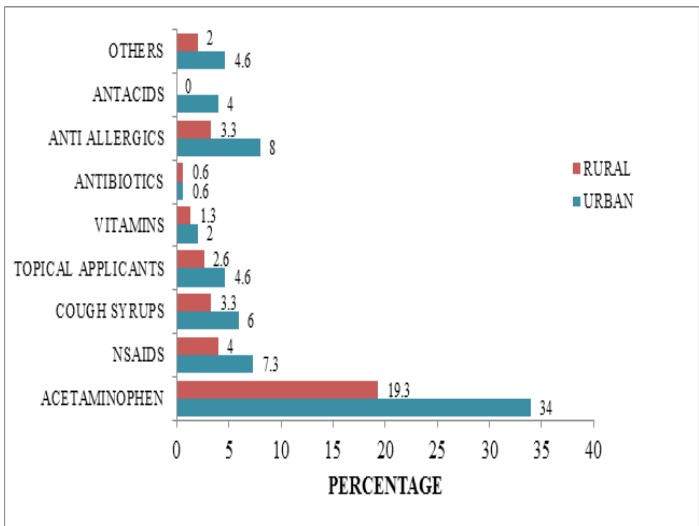

Figure 1: Categories of medicines stored other than prescription medicines.

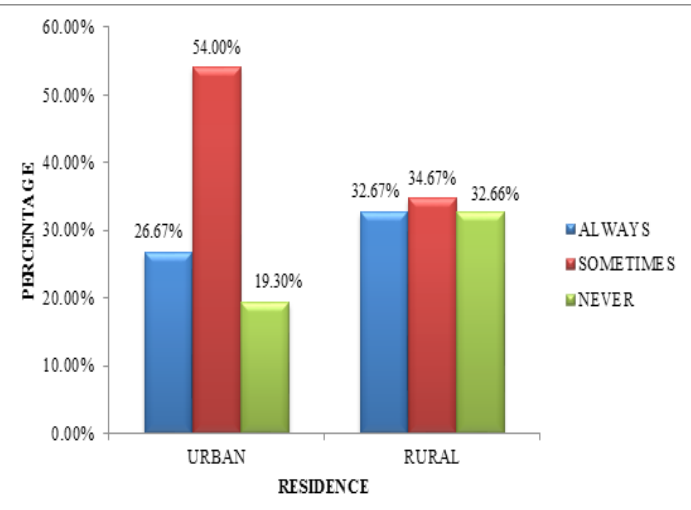

Figure 2: Distribution of urban and rural participants based on practice of self-medication.

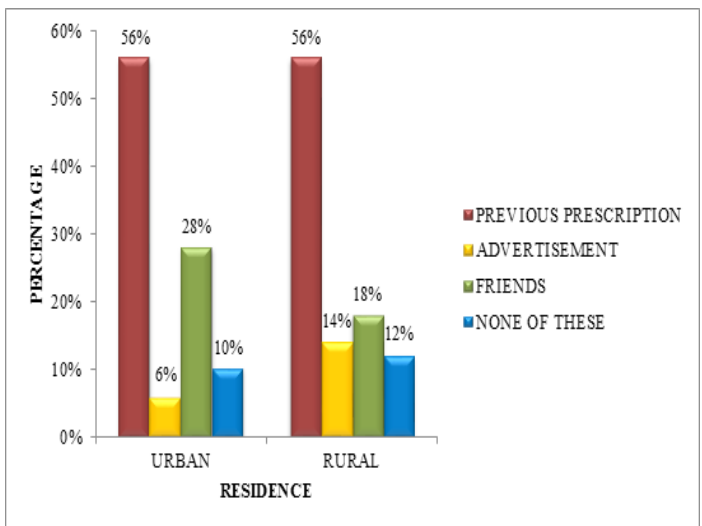

Figure 3: Distribution of urban and rural participants based on source for self-medication.

proportion of self-medication practice was noticed among the young adults. However we observed that there is no statistically significant relationship between age and use of self-medication.

The study by Aqeel et al. also showed that most of the people self-medicated on their own initiative. ${ }^{15}$ In our study the most common source of self-medication in both urban and rural communities was found to be the previous prescriptions. Apart from this advertisement 
had major influence among rural community, whereas the urban population had suggestion from friends as one of the major source of self-medication. Risk of drug related problem increases alarmingly while using medicines by friend's advices and advertisements. There is a need for strict monitoring of misleading advertisements and information about medicines in media.

\section{CONCLUSION}

Our study concludes that there is significant difference in drug use behaviour and pattern between urban and rural communities and also both communities have their own imperfections with the drug use pattern. The extent of self-medication and medicine storage behaviour is widespread in urban community, whereas rural population is less adhered to their given medication. Improper disposal of drugs are alarmingly large and similar in both populations.

This strongly suggests the need for implementation of population need-based awareness programmes in both rural and urban communities. Doctors, pharmacists, nurses and other public health professionals along with the governing bodies should come forward to achieve the same goal.

\section{ACKNOWLEDGEMENT}

We wish to express our sincere thanks to those who have helped us in completion of this work without which this work would not have reached its destination.

\section{CONFLICT OF INTEREST}

The authors declare no conflict of interest.

\section{ABBREVIATIONS}

SPSS: Statistical package for social sciences.

\section{SUMMARY}

Essential medicines are defined as those that satisfy the health care needs of majority of the population. The selection of essential medicines needs to be followed by appropriate use and improvement of the quality of health care. Inadequate communication between patients and health professionals due to time constraints leads to improper use of medicines. People being unaware of the side effects of drugs leads to the unsafe use of medicines. It is necessary to ensure that drug use in a community is congruent with drug needs and confers maximum therapeutic benefits and minimal adverse reactions.

\section{REFERENCES}

1. World Health Organization. How to investigate the use of medicines by consumers. Geneva: World Health Organization. 2004.

2. Hughes CM, McElnay JC, Fleming GF. Benefits and risks of self-medication. Drug safety. 2001;24(14):1027-3

3. DeBolle L, Mehuys E, Adriaens E, Remon JP, VanBortel L, Christiaens T. Home medication cabinets and self-medication: A source of potential health threats? Annals of Pharmacotherapy. 2008;42(4):572-9.

4. Prabhu VA, Naik V, Doddapaneni S, Mateti UV, Nagappa AN. A survey on medicines safety and usage in community pharmacy. Journal of Basic and Clinical Pharmacy. 2013;5(1):24.

5. Mirza N, Ganguly B. Utilization of Medicines Available at Home by General Population of Rural and Urban Set up of Western India. Journal of Clinical and Diagnostic Research. 2016;10(8):FC05.

6. Beyene K, Aspden T, Sheridan J. Prescription medicine sharing: Exploring patients' beliefs and experiences. J Pharm Policy Pract. 2016;9(1):23.

7. Dawood OT, Hassali MA, Saleem F. Factor's affecting knowledge and practice of medicine use among the general public in the State of Penang, Malaysia. Journal of Pharmaceutical Health Services Research. 2017;8(1):51-7.

8. Soleymani F, Ahmadizar F, Meysamie A, Abdollahi M. A survey on the factors influencing the pattern of medicine's use: Concerns on irrational use of drugs. Journal of Research in Pharmacy Practice. 2013;2(2):59.

9. Khan MU, Khan AN, Ahmed FR, Feroz Z, Rizvi SA, Shah S, et al. Patients' opinion of pharmacists and their roles in health care system in Pakistan. Journal of Young Pharmacists. 2013;5(3):90-4.

10. Akici A, Aydin V, Kiroglu A. Assessment of the association between drug disposal practices and drug use and storage behaviors. Saudi Pharmaceutical Journal. 2018;26(1):7-13.

11. Law LV, Sakharkar P, Zargarzadeh A, Tai BW, Hess K, Hata M, et al. Taking stock of medication wastage: Unused medications in US households. Res Soc Adm Pharm. 2015;11(4):571-8.

12. Imran M. The prevalence and patterns of usage of Ayurveda, Unani and home remedies in younger adults of rural North India. International Journal of Green Pharmacy. 2017;11(02).

13. Banerjee I, Bhadury T. Self-medication practice among undergraduate medical students in a tertiary care medical college, West Bengal. Journal of Postgraduate Medicine. 2012;58(2):127.

14. Limaye D, Limaye V, Fortwengel G, Krause G. Self-medication practices in urban and rural areas of western India: A cross sectional study. International Journal of Community Medicine and Public Health. 2018;5(7):2672-85.

15. Aqeel T, Shabbir A, Basharat H, Bukhari M, Mobin S, Shahid H, et al. Prevalence of self-medication among urban and rural population of Islamabad, Pakistan. Tropical Journal of Pharmaceutical Research. 2014;13(4):627-33. 